\title{
La muerte en las letras y en otros escenarios...Necrología del $2014^{1}$ \\ Por Norma Esther García Meza²
}

\author{
“... ya nos has quitado padres, madres, hijos y tíos por \\ montones. \\ Hoy queremos estar con ellos y sin ti; \\ charlar sin que nos escuches; \\ deliberar sobre asuntos que no te incumben; \\ amarnos como tú no sabes ni sabrás nunca; \\ vivir la vida dulce, la puta vida amarga. \\ Muerte, déjanos en paz"
}

Pedro Miguel

Desde noviembre de 2010, el Centro de Estudios de la Cultura y la Comunicación, de la Universidad Veracruzana, ha realizado cada año un evento sobre cultura funeraria, en el marco de las actividades de la línea de investigación Prácticas culturales y construcción de la memoria. Consiste, en primer lugar, en la colocación de un altar dedicado a algún personaje recientemente fallecido, cuya vida y obra consideramos significativa y entrañable. Se trata de un altar heterodoxo y creativo, elaborado con los recursos materiales y simbólicos a nuestro alcance, en el que cada participante despliega lo poco o lo mucho de sus saberes sobre los elementos que deben incluirse, como el copal, la sal, el agua, el arco, los niveles y el camino con los pétalos anaranjados... Así, desde la fugacidad de una simple fotocopia, en la que imprimimos su nombre o su rostro, y desde la humildad del cempasúchil, del pan de muerto y de las veladoras encendidas, hemos celebrado y agradecido en estos años a personajes significativos en el ámbito de la cultura y de la comunicación, pero también a personajes cuya muerte revela algunas de las múltiples problemáticas de nuestro complejo y convulsionado presente.

Paralelamente, se han organizado exposiciones fotográficas sobre el tema y hemos cerrado los eventos con una o más mesas en las que han participado colegas de nuestra universidad y de otras instituciones hermanas, y en las que hemos compartido reflexiones en torno a los discursos o prácticas asociadas a la memoria de la muerte. Pero en ninguna de las anteriores ocasiones habíamos elaborado una necrología, es decir, una "noticia comentada acerca de una persona muerta hace poco tiempo". ${ }^{3}$

1.- Este texto fue elaborado con la colaboración de Hazel Hernández Guerrero, becaria Conacyt, Centro de Estudios de la Cultura y la Comunicación, Universidad Veracruzana, y una versión preliminar del mismo fue presentada en la mesa La muerte en las letras y otros escenarios, de las Jornadas Funerarias de 2014.

2.- Doctora en Letras por la UNAM. Miembro del Sistema Nacional de Investigadores nivel I. Investigadora de tiempo completo en el Centro de Estudios de la Cultura y la Comunicación de la Universidad Veracruzana. 3.- Diccionario de la Lengua Española (DRAE), 23a edición, 2014. 
La decisión de elaborarla ahora responde, sin duda, a que nunca antes la muerte había rondado, tan insistente y dolorosamente, por las letras y otros escenarios, como en el 2014. Nunca antes habíamos tenido a tantos poetas, escritores, pensadores, luchadores sociales, pintores, fotógrafos, periodistas, músicos, cantantes, coreógrafos, bailarines, actores, actrices $\mathrm{y}$, reciente y lamentablemente, estudiantes, a quienes dedicar nuestro altar. Sesenta y seis nombres conforman esta necrología, sesenta y seis muertes que no queremos olvidar... para ellos es nuestro altar. ${ }^{4}$

Comencemos entonces...

\title{
Enero
}

Manuel Ahumada

Guillermo Arriaga Fernández

Juan Gelman

Marco Fonz

José Emilio Pacheco

Sergio Loo

Félix Grande

El viernes 3 de enero murieron el ilustrador, historietista, pintor y monero Manuel Ahumada y el bailarín y coreógrafo Guillermo Arriaga Fernández. En el transcurso del mes murieron cinco poetas: el martes 14, Juan Gelman; el miércoles 22, Marco Fonz; el domingo 26, José Emilio Pacheco; el lunes 27, Sergio Loo y el jueves 30, Félix Grande.

\section{Febrero}

\author{
Mariano Flores Castro \\ Stuart Hall \\ Gregorio Jiménez \\ Federico Campbell \\ Enrique Nery \\ Paco de Lucía
}

El miércoles 5 de febrero murió el poeta, narrador y crítico de arte Mariano Flores Castro; el lunes 10 murió el teórico de los estudios culturales Stuart Hall y el martes 11 fue asesinado el periodista veracruzano Gregorio Jiménez. Cuatro días después, el sábado 15, murió el escritor Federico 
Campbell; el sábado 22, el jazzista mexicano Enrique Nery y el miércoles 26, el guitarrista flamenco Paco de Lucía.

\section{Marzo}

\section{Luis Villoro}

Helena Paz Garro

El primer miércoles de marzo murió el filósofo Luis Villoro y el último domingo, 30 de marzo, murió Helena Paz Garro, la única hija de los escritores Elena Garro y Octavio Paz.

\section{Abril}

\section{Lin Durán \\ Gabriel García Márquez \\ Emmanuel Carballo}

El 16 de abril murió Lin Durán, bailarina, coreógrafa y una de las más importantes teóricas de la danza en el país. Al otro día, jueves 17, murió el escritor Gabriel García Márquez y el domingo 20, el crítico literario Emmanuel Carballo.

\section{Mayo}

\section{Juan Formell \\ Francisco Icaza \\ Carmen Alardín}

En mayo murieron el legendario músico cubano Juan Formell, fundador de los Van Van (jueves 1), el pintor Francisco Icaza (sábado 3) y la poeta Carmen Alardín (sábado 10).

\section{Junio}

Manuel Álvarez Ortega

María Luisa Landín

Ana María Matute

Aurora Agüeria

Arnaldo Córdova 
El lunes 16 de junio murió el poeta español Manuel Álvarez Ortega; el viernes 20, "la reina del bolero", María Luisa Landín; el miércoles 25, la escritora Ana María Matute; el viernes 27, la bailarina y coreógrafa Aurora Agüeria y el lunes 30, el politólogo e historiador Arnaldo Córdova.

\section{Julio}
Charlie Haden
Nadine Gordimer
Johnny Winter
Joao Ubaldo Ribeiro
Rubem Alves
Ariano Suassuna

El viernes 11 de julio murió el contrabajista y precursor del free jazz, Charlie Haden. El domingo 13 murió la escritora Nadine Gordimer. El miércoles 16, el guitarrista de blues Johnny Winter. El viernes 18, el escritor Joao Ubaldo Ribeiro. El sábado 19 se fue el escritor, educador y teólogo brasileño -considerado el padre intelectual de la Teología de la Liberación- Rubem Alves y, cuatro días después, el escritor, dramaturgo y poeta brasileño Ariano Suassuna.

\section{Agosto}

Rafael Santa Cruz
Robin Williams
Maruxa Vilalta
Tehua
María Eugenia Llamas

En agosto murieron el músico y actor peruano Rafael Santa Cruz (lunes 4), el actor estadounidense Robin Williams (lunes 11), la dramaturga mexicana Maruxa Vilalta (martes 19), la cantante Tehua (jueves 21) y la actriz María Eugenia Llamas (domingo 31).

\section{Septiembre}

Gustavo Cerati

China Zorrilla

Raúl Álvarez Garín

Luis Nishizawa 
Víctimas del ataque armado del 26 y 27 de septiembre en Iguala, Guerrero:

\author{
Daniel Solís Gallardo \\ Julio César Mondragón \\ Julio César Ramírez Nava \\ Víctor Manuel Lugo Ortiz \\ David Josué García Evangelista \\ Blanca Montiel Sánchez
}

El mes de septiembre fue el más atroz: el jueves 4 murió el músico Gustavo Cerati; el miércoles 17, la actriz China Zorrilla; la mañana del viernes 26 murió el luchador social y personaje emblemático del 68, Raúl Álvarez Garín. Durante la noche de ese mismo viernes 26 y la madrugada del sábado 27, en Iguala, Guerrero, tuvo lugar un violento ataque contra los estudiantes de la Normal Rural de Ayotzinapa y fueron asesinados: Daniel Solís Gallardo, Julio César Mondragón y Julio César Ramírez Nava. También murieron en el ataque el chofer Víctor Manuel Lugo Ortiz y el joven futbolista David Josué García Evangelista, quienes iban en uno de los autobuses que fueron baleados por los pistoleros, así como la señora Blanca Montiel Sánchez, quien pasaba en un taxi por el lugar, y en el que 43 estudiantes fueron víctimas de desaparición forzada.

El lunes 29 murió el pintor, escultor, vitralista, grabador y muralista Luis Nishizawa.

\title{
Octubre
}

\section{René Burri}

Jorge Saldaña

Estudiantes asesinados en el mes de octubre:

Ricardo de Jesús Esparza Villegas

Isaac Eduardo Osorio Franchini

El lunes 20 de octubre murió el fotógrafo suizo René Burri, autor de la famosa foto de Ernesto Che Guevara fumando un puro. El domingo 19, encontraron asesinado al estudiante de la Universidad de Guadalajara Ricardo de Jesús Esparza Villegas. El jueves 30 de octubre murió el periodista compositor, escritor y locutor de radio y televisión, Jorge Saldaña y ese mismo día fue asesinado Isaac Eduardo Osorio Franchini, egresado de la Facultad de Medicina Forense de la Universidad Veracruzana, Región Veracruz-Boca del Río. 


\title{
Noviembre
}

Enrique Velasco Ugalde

José Yurrieta Valdés

Manitas de Plata

Raymond Almiran M.

Lucien Clergue

Roberto Gómez Bolaños

El martes 4 de noviembre murieron el comunicólogo Enrique Velasco Ugalde, fundador de la Universidad Autónoma Metropolitana (UAM) y promotor de la radio educativa, cultural y de servicio en México, así como José Yurrieta Valdés, escritor, humanista y decano de la Universidad Autónoma del Estado de México, de la que también fue fundador. $\mathrm{Al}$ otro día, miércoles 5 , murió el guitarrista gitano Manitas de Plata. El domingo 9, murió el escritor Raymond Almiran Montgomery y el sábado siguiente murió el fotógrafo francés Lucien Clergue. El último viernes de noviembre murió el actor Roberto Gómez Bolaños.

\section{Diciembre}

\author{
Bobby Keys \\ Vicente Leñero \\ Luis Herrera de la Fuente \\ Giuseppe Pino Mango \\ Virna Lisi \\ Gerardo Deniz \\ Jane Brown \\ Horacio Ferrer \\ Joe Cocker \\ Luise Rainer
}

El martes 2 de diciembre murió el saxofonista de los Rolling Stones, Bobby Keys. Al día siguiente murió el escritor Vicente Leñero. El viernes 5, murió el músico, escritor y promotor cultural Luis Herrera de la Fuente. El cantautor italiano Giuseppe Pino Mango murió el domingo 7 y el jueves 18, la actriz italiana Virna Lisi. El sábado 20 murió el poeta Gerardo Deniz y el domingo 21 murieron la fotógrafa británica Jane Brown, el poeta uruguayo Horacio Ferrer y el músico británico de rock Joe Cocker. El último martes de diciembre murió la actriz Luise Rainer.

\section{Reflexión final}


Mucho, poco o nada tuvieron en común algunos de los que murieron este 2014, pero a nosotros, que fuimos sus lectores o parte de su público, que nos conmovimos con sus poemas, con sus novelas, con su música, con sus ideas o, en el caso de las víctimas de la violencia, con la manera terrible en que murieron, nos duele su partida. Hoy los honramos y agradecemos su legado.

Por su importancia y trascendencia, por su significación, quiero cerrar esta necrología recordando las palabras que José Emilio Pacheco dijo al recibir el Premio Cervantes:

Nada de lo que ocurre en este cruel 2010 -de los terremotos a la nube de ceniza, de la miseria creciente a la inusitada violencia que devasta a países como Méxicoera previsible al comenzar el año. Todo cambia día a día, todo se corrompe, todo se destruye. Sin embargo, en medio de la catástrofe, al centro del horror que nos cerca por todas partes, siguen en pie, y hoy como nunca son capaces de darnos respuestas, el misterio y la gloria del Quijote. ${ }^{5}$

Con el eco de sus sabias palabras, digo con él: Nada de lo que ocurre en este cruel 2014 - ni la virulencia de las reformas, ni la cantidad de muertos y desaparecidos de este sexenio, incluyendo los terribles e indignantes casos de Tlatlaya y Ayotzinapa, ni la muerte rondando por las letras y otros escenarios- era previsible al comenzar el año. Todo cambia día a día, todo se corrompe, todo se destruye. Sin embargo en medio de la catástrofe, al centro del horror que nos cerca por todas partes, siguen en pie, $y$ hoy como nunca son capaces de darnos respuestas... las aportaciones que todos y cada uno de estos personajes entrañables hicieron a la cultura de nuestro tiempo, a nuestra educación sentimental, a nuestra particular visión del mundo y a nuestro sentido de pertenencia a esta gran comarca llamada México, en la que se celebra la muerte porque amamos la vida. ${ }^{6}$

\section{Bibliografía 7}

FLORES, Alondra, Ángel Vargas y Reyes Martínez. "Murió Manuel Ahumada, una voz insustituible en la narrativa gráfica", La Jornada. núm. 10777, año 30, México, 4 de agosto de 2014, consultado

5.- En el sitio http://www.jornada.unam.mx/2010/04/24/cultura/ao4n1cul, consultado el 14 de octubre de 2014 .

6.- Como parte del homenaje rendido a los 43 estudiantes desaparecidos en Iguala, Guerrero, la lectura del presente texto cerró con la siguiente declaración: "Precisamente porque amamos la vida, desde esta mesa unimos nuestra voz a las miles de voces y decimos: iVivos se los llevaron, vivos los queremos!”

7.- Manteniendo la forma de la necrología y para facilitar la ubicación de las fuentes en el texto, la lista de referencias no emplea el orden alfabético sino el orden de su aparición en el capítulo, o sea, el orden cronológico. 
el 3 de octubre de 2014, disponible en: http://www.jornada.unam. $\mathrm{mx} / 2014 / 01 / 04 /$ politica/o1on1pol.

VARGAS, Ángel. "Fallece el bailarín y coreógrafo mexicano Guillermo Arriaga Fernández”. La Jornada. Núm. 10566, año 30, México, 4 de enero de 2014, p. 2, consultado el 3 de octubre de 2014, disponible en: http://www.jornada.unam.mx/ultimas/2014/o1/o3/ fallece-el-bailarin-y-coreografo-mexicano-guillermo-arriaga-fernandez-3839.html.

"Fallece el poeta Juan Gelman a los 83 años", La Jornada en línea. México, 14 de enero de 2014, consultado el 3 de octubre de 2014, disponible en: http://www.jornada.unam.mx/ultimas/2014/01/14/ fallece-el-poeta-juan-gelman-a-los-82-anos-2425.html.

MONTAÑO GARFIAS, Ericka. "Marco Fonz se suicidó; que al final estoy tan solo como un verso, decía", La Jornada. Núm. 10587, año 30, México, 25 de enero de 2014, p. 5, consultado el 3 de octubre de 2014, disponible en: http://www.jornada.unam.mx/2014/o1/25/ cultura/a05n1cul.

MACMASTERS y Merry Afp. "Fallece el escritor mexicano José Emilio Pacheco", La Jornada en línea. México, 26 de enero de 2014, consultado el 3 de octubre de 2014, disponible en: http://www.jornada.unam.mx/ultimas/2014/o1/26/fallece-el-escritor-mexicano-jose-emilio-pacheco-1264.html.

RODRÍGUEZ, Ana Mónica. "Muere el joven poeta Sergio Loo; fue un irreverente y poco creído de las famas", La Jornada. Núm. 10591, año 30, México, 29 de enero de 2014, p. 4, consultado el 3 de octubre de 2014, disponible en: http://www.jornada.unam. $\mathrm{mx} / 2014 / 01 / 29 /$ cultura/a04n1cul.

TEJEDA, Armando G. "Muere Félix Grande; de nuevo el mundo de la poesía está de luto", La Jornada. Núm. 10593, año 30, México, 31 de enero de 2014, p. 4, consultado el 3 de octubre de 2014, disponible en: http://www.jornada.unam.mx/2014/o1/31/cultura/ao4n$1 \mathrm{cul}$.

REDACCIÓN. "Falleció el poeta y promotor cultural Mariano Flores Castro", La Jornada en línea. México, 5 de febrero, consultado el 5 de octubre de 2014, disponible en: http://www.jornada.unam.mx/ ultimas/2014/02/05/fallecio-el-poeta-y-promotor-cultural-mariano-flores-castro-5427.html.

ALBORES, Jesús. "Stuart Hall, mentor de los estudios culturales", ElPaís.com. Madrid, 9 de marzo, consultado el 5 de octubre de 2014, disponible en: http://sociedad.elpais.com/sociedad/2014/03/09/ actualidad/1394321323_069352.html. 
"Hallan sin vida a reportero secuestrado en Veracruz", La Jornada en línea. México, 11 de febrero de 2014, consultado el 5 de octubre de 2014, disponible en: http://www.jornada.unam.mx/ultimas/2014/o2/11/hallan-sin-vida-a-reportero-secuestrado-en-veracruz-8191.html.

"Murió el escritor Federico Campbell tras derrame masivo, a los 72 años”, La Jornada en línea. México, 15 de febrero de 2014, consultado el 5 de octubre de 2014, disponible en: http://www.jornada. unam.mx/ultimas/2014/02/15/desconectaran-al-escritor-federico-campbell-tras-sufrir-derrame-masivo-informo-jaime-chaidez-9571.html.

CRUZ BÁRCENAS, Arturo. "Murió Enrique Nery, uno de los pioneros del jazz en México”, La Jornada. Núm. 10617, año 30, México, 24 de febrero de 2014, p. 12, consultado el 5 de octubre de 2014, disponible en: http://www.jornada.unam.mx/2014/o2/24/espectaculos/a12n1esp.

TEJEDA, Armando. "Murió Paco de Lucía, el pescador de Algeciras que revolucionó el flamenco", La Jornada. Núm. 10620, año 30, México, 27 de febrero de 2014, p. 2, consultado el 5 de octubre de 2014, disponible en: http://www.jornada.unam.mx/2014/o2/27/espectaculos/ao2n1esp.

MONTAÑO GARFIAS, Ericka. "Muere Luis Villoro, filósofo de la política y la acción social”, La Jornada en Línea. México, 5 de marzo de 2014, consultado el 5 de octubre de 2014, disponible en: http:// www.jornada.unam.mx/ultimas/2014/03/05/fallece-el-filosofo-mexicano-luis-villoro-a-los-91-anos-4315.html.

MORELOS, Rubicela. "Fallece Helena Paz Garro, a los 74 años”, La Jornada. Núm. 10652, año 30, México, 31 de marzo de 2014, p. 9, consultado el 5 de octubre de 2014, disponible en: http://www. jornada.unam.mx/2014/o3/31/cultura/ao9n1cul.

MATEOS-VEGA, Mónica, 2014, "Muere Lin Durán, académica de la danza", en la Jornada, 18 de abril, año treinta, núm. 10670, México, p. 3 http://www.jornada.unam.mx/2014/o4/18/cultura/ao3n1 cul (consultado el 5 de octubre de 2014).

MONTAÑO GARFIAS, Ericka, 2014, "Hasta siempre, Gabriel García Márquez", en La Jornada en Línea, 17 de abril, Mèxico. http:// www.jornada.unam.mx/ultimas/2014/04/17/fallece-gabriel-garcia-marquez-6659.html (consultado el 5 de octubre de 2014).

MACMASTERS, Merry, 2014, "Muere el crítico literario Emmanuel Carballo", en La Jornada en Línea, 20 de abril, México. http:// www.jornada.unam.mx/ultimas/2014/04/20/muere-el-critico-li- 
terario-emmanuel-carballo-6812.html (consultado el 5 de octubre de 2014).

OLIVARES, Juan José, 2014, "Fallece el legendario músico cubano Juan Formell, fundador de los Van Van”, en La Jornada en Línea, o1 de mayo, México. http://www.jornada.unam.mx/ultimas/2014/05/o1/fallece-el-legendario-musico-cubano-juan-formell-fundador-de-los-van-van-9352.html (consultado el 5 de octubre de 2014).

DPA. "Falleció a los 84 años el pintor Francisco Icaza", en La Jornada en Línea, 03 de mayo, Mèxico. http://www.jornada.unam.mx/ultimas/2014/05/o3/muere-el-pintor-mexicano-francisco-icaza-1068. html (consultado el 5 de octubre de 2014).

NOTIMEX, "2014, "Muere la poeta mexicana Carmen Alardín, Premio Xavier Villaurrutia”, en La Jornada en Línea, 10 de mayo, México.http://www.jornada.unam.mx/ultimas/2014/o5/10/muere-la-poeta-mexicana-carmen-alardin-premio-xavier-villaurrutia-7762.html (consultado el 5 de octubre de 2014).

EFE, 2014, "Muere El poeta cordobés Manuel Álvarez Ortega", en $A B C$. es / Cultura, 16 de junio, Madrid. http://www.abc.es/cultura/libros/20140615/abci-muere-poeta-alvarez-ortega-201406151308. html (consultado el 5 de octubre de 2014).

NOTIMEX, "2014, "Falleció a los 92 años María Luisa Landín, "la reina del bolero”, en La Jornada en Línea, 21 de junio, México. http:// www.jornada.unam.mx/ultimas/2014/o6/21/fallecio-la-cantantemaria-luisa-landin-a-los-93-anos-4894.html (consultado el 5 de octubre de 2014).

AP. 2014, "Muere la escritora española Ana María Matute", en La Jornada en Línea, 25 de Junio, México. http://www.jornada.unam. $\mathrm{mx} /$ ultimas/2014/o6/25/muere-la-escritora-espanola-ana-maria-matute-777.html (consultado el 5 de octubre de 2014).

PALAPA QUIJAS, Fabiola, 2014" Fallece Aurora Agüeria, una de las grandes figuras de la danza en el país" en la Jornada, 5 de julio, año treinta, núm. 10747, México, p. a 11. http://www.jornada. unam.mx/2014/07/05/cultura/a11n1cul (consultado el 5 de octubre de 2014).

REDACCIÓN. "Fallece el politólogo e historiador Arnaldo Córdova", La Jornada en línea. México, 30 de junio de 2014, consultado el 5 de octubre de 2014, disponible en: http://www.jornada.unam.mx/ultimas/2014/06/30/fallece-en-doctor-arnaldo-cordova-8648.html.

AFP. "Murió el jazzista Charlie Haden", La Jornada en línea. México, 12 de julio de 2014, consultado el 6 de octubre de 2014, disponi- 
ble en: http://www.jornada.unam.mx/ultimas/2014/o7/12/murio-el-jazzista-charlie-haden-3783.html.

AFP, DPA y PL. "Muere Nadine Gordimer, tenaz luchadora contra el apartheid", La Jornada. Núm. 10757, año 30, México, 5 de julio de 2014, p. 4, consultado el 6 de octubre de 2014, disponible en: http://www.jornada.unam.mx/2014/o7/15/cultura/a04n1cul.

DPA. "Fallece la leyenda del blues Johnny Winter a los 70 años", La Jornada en Línea. México, 17 de julio de 2014, consultado el 6 de octubre de 2014, disponible en: http://www.jornada.unam.mx/ ultimas/2014/07/17/fallece-la-leyenda-del-blues-johnny-winter-alos-70-anos-5461.html.

. "Fallece el escritor brasileño Joao Ubaldo Ribeiro", La Jornada en Línea. México, 18 de julio, consultado el 6 de octubre de 2014, disponible en: http://www.jornada.unam.mx/ultimas/2014/o7/18/fallece-el-escritor-brasileno-joao-ubaldo-ribeiro-7971.html.

"Muere Rubem Alves, padre intelectual de la Teología de la Liberación”, La Jornada en Línea, México, 19 de julio de 2014, consultado el 6 de octubre de 2014, disponible en: http://www. jornada.unam.mx/ultimas/2014/o7/19/muere-rubem-alves-padre-intelectual-de-la-teologia-de-la-liberacion-5855.html.

AFP. "Fallece el escritor y dramaturgo brasileño Ariano Suassuna", $L a$ Jornada en línea. México, 23 de julio de 2014, consultado el 6 de octubre de 2014, disponible en: http://www.jornada.unam.mx/ ultimas/2014/07/23/fallece-el-escritor-y-dramaturgo-brasileno-ariano-suassuna-9854.html.

. "Muere músico y actor afroperuano Rafael Santa Cruz", $L a$ Jornada en línea. México, 4 de agosto de 2014, consultado el 10 de octubre de 2014, disponible en: http://www.jornada.unam. $\mathrm{mx} /$ ultimas/2014/o8/o4/muere-musico-y-actor-afroperuano-rafael-santa-cruz-3118.html.

NOTIMEX, REUTERS y AP. "Falleció el actor Robin Williams; presumen suicidio”, La Jornada. Núm. 10785, año 30, México, 12 de agosto de 2014, p. 10, consultado el 10 de octubre de 2014, disponible en: http://www.jornada.unam.mx/2014/o8/12/espectaculos/ a10n1esp.

NOTIMEX. "Fallece la dramaturga mexicana Maruxa Vilalta", La Jornada en Línea. México, 19 de agosto de 2014, consultado el 10 de octubre de 2014, disponible en: http://www.jornada.unam.mx/ ultimas/2014/o8/19/fallece-la-dramaturga-mexicana-maruxa-vilalta-345o.html. 
CRUZ BÁRCENAS, Arturo. "Falleció a los 71 años la cantante queretana Tehua", La Jornada en línea. México, 21 de agosto de 2014, consultado el 10 de octubre de 2014, disponible en: http://www.jornada.unam.mx/ultimas/2014/o8/21/fallecio-a-los-71-anos-la-cantante-queretana-tehua-2756.html

NOTIMEX. "Fallece la actriz María Eugenia Llamas La Tucita”, La Jornada en Línea. México, 10 de septiembre de 2014, consultado el 10 de octubre de 2014, disponible en: http://www.jornada.unam.mx/ ultimas/2014/o9/01/fallece-la-actriz-maria-eugenia-llamas-la-tucita-7656.html.

REUTERS. "Murió Gustavo Cerati, luego de cuatro años en coma", La Jornada en Línea. México, 4 de septiembre de 2014, consultado el 12 de octubre de 2014, disponible en: http://www.jornada.unam. $\mathrm{mx} /$ ultimas/2014/o9/04/muere-gustavo-cerati-a-los-55-anos-deedad-9227.html.

"Murió la prolífica actriz China Zorrilla en Montevideo", La Jornada. Núm. 10621, año 30, México, 18 de septiembre de 2014, p. 8, consultado el 12 de octubre de 2014, disponible en: http://www.jornada.unam.mx/2014/o9/18/espectaculos/ao8n3esp.

MARTÍNEZ, Fabiola. “Murió Raúl Álvarez Garín”, La Jornada en Línea. México, 27 de septiembre de 2014, consultado el 12 de octubre de 2014, disponible en: http://www.jornada.unam.mx/ultimas/2014/o9/27/murio-raul-alvarez-garin-6426.html.

OCAMPO ARISTA, Sergio. "Policías balean a normalistas de Ayotzinapa en Iguala; 5 muertos", La Jornada. Núm. 10831, año 30, México, 28 de septiembre de 2014, p. 5, consultado el 12 de octubre de 2014, disponible en: http://www.jornada.unam.mx/2014/o9/28/ politica/005n1pol.

MACMASTERS, Merry y Mónica Mateos-Vega. "Murió Luis Nishizawa; se fue como los grandes, dice su hijo", La Jornada. Núm. 10833, año 30, México, 30 de septiembre de 2014, p. 14, consultado el 12 de octubre de 2014, disponible en: http://www.jornada.unam. $\mathrm{mx} / 2014 / 09 / 30 /$ cultura/a04n1cul.

AFP. "Muere René Burri, legendario fotógrafo que inmortalizó al Che", La Jornada en línea. México, 20 de octubre de 2014, consultado el 24 de octubre de 2014, disponible en: http://www.jornada.unam. $\mathrm{mx} /$ ultimas/2014/10/20/muere-rene-burri-legendario-fotografo-que-inmortalizo-al-che-6168.html.

FERRER, Mauricio y Juan Carlos G. Partida. "Murió Luis Nishizawa; se fue como los grandes, dice su hijo", La Jornada. Núm. 10856, año 30, México, 23 de octubre de 2014, p. 36, consultado el 30 
de octubre de 2014, disponible en: http://www.jornada.unam. $\mathrm{mx} / 2014 / 10 / 23 /$ estados/o36n1est.

WHALEY, Jaime. "Falleció a los 83 años el periodista Jorge Saldaña", La Jornada en línea. México, 31 de octubre de 2014, consultado el 31 de octubre de 2014, disponible en: http://www.jornada.unam. $\mathrm{mx} /$ ultimas/2014/10/31/fallecio-a-los-83-anos-el-periodista-jorge-saldana-7486.html.

RODRÍGUEZ PESTAÑA, Juan Carlos. "El joven asesinado era técnico histotecnólogo y embalsamador, egresado de Medicina Forense-UV", Al Calor Político.com. Veracruz, México, 30 de octubre de 2014, consultado el 3 de noviembre de 2014, disponible en: http:// www.alcalorpolitico.com/informacion/el-joven-asesinado-era-tecnico-histotecnologo-y-embalsamador-egresado-de-medicina-forense-uv-152730.html\#.VNt9mbdMvcs.

AMADOR TELLO, Judith. "Muere Enrique Velasco Ugalde, fundador de la UAM”, Proceso.com. México, 4 de noviembre de 2014, consultado el 5 de noviembre de 2014, disponible en: http://www.proceso. com.mx/?p=386694.

REDACCIÓN. "UAEM de luto: falleció José Yurrieta”, Portal. México, 3 de noviembre de 2014, consultado el 5 de noviembre de 2014, disponible en: http://diarioportal.com/destacada/uaem-de-luto-fallecio-jose-yurrieta/.

. "Muere Manitas de Plata, famoso gitano virtuoso del flamenco", La Jornada en línea. México, 6 de noviembre de 2014, consultado el 14 de febrero de 2015, disponible en: http://www.jornada.unam. $\mathrm{mx} /$ ultimas/2014/11/o6/muere-manitas-de-plata-famoso-guitarrista-gitano-7041.html.

AP. "Fallece el escritor Raymond Almiran Montgomery", La Jornada en línea. México, 16 de noviembre de 2014, consultado el 14 de febrero de 2015, disponible en: http://www.jornada.unam. $\mathrm{mx} / 2014 / 11 / 16 /$ cultura/ao6n2cul.

AFP. "Muere el fotógrafo francés Lucien Clergue”. La Jornada. Núm. 10880, año 31, México, 16 de noviembre de 2014, p. 6, consultado el 14 de febrero de 2015, disponible en: http://www.jornada.unam. $\mathrm{mx} / 2014 / 11 / 16 /$ cultura/ao6n3cul.

AGENCIAS. "Falleció Roberto Gómez Bolaños Chespirito a los 85 años”, La Jornada en línea. México, 28 de noviembre de 2014, consultado el 14 de febrero de 2015, disponible en: http://www. jornada.unam.mx/ultimas/2014/11/28/fallece-roberto-gomez-bolanos-a-los-85-anos-8061.html.

AP. "Muere saxofonista de los Rolling Stones, Bobby Keys" a los 85 
años”, La Jornada en línea. México, 2 de diciembre de 2014, consultado el 14 de febrero de 2015, disponible en: http://www.jornada.unam.mx/ultimas/2014/12/o2/muere-saxofonista-de-los-rolling-stones-bobby-keys-8335.html.

MACMASTERS, Merry y Ana Mónica Rodríguez. "Muere el escritor Vicente Leñero; homenaje este jueves en Bellas Artes”. La Jornada en línea. México, 3 de diciembre de 2014, consultado el 14 de febrero de 2015, disponible en: http://www.jornada.unam.mx/ ultimas/2014/12/03/muere-el-escritor-vicente-lenero-a-los-81anos-8470.html.

VARGAS, Ángel. "Muere Herrera de la Fuente, ícono del arte del siglo XX mexicano", La Jornada en línea. México, 5 de diciembre de 2014, consultado el 14 de febrero de 2015, disponible en: http:// www.jornada.unam.mx/ultimas/2014/12/05/fallece-luis-herrera-de-la-fuente-8478.html.

AFP. "Muere el cantautor italiano Giuseppe Pino Mango", La Jornada en línea. México, 8 de diciembre de 2014, consultado el 14 de febrero de 2015, disponible en: http://www.jornada.unam.mx/ ultimas/2014/12/o8/muere-el-cantautor-italiano-giuseppe-pino-mango-8296.html.

NOTIMEX. "Muere la actriz italiana Virna Lisi a los 78 años de edad", La Jornada en línea. México, 18 de diciembre de 2014, consultado el 14 de febrero de 2015, disponible en: http://www.jornada.unam. $\mathrm{mx} /$ ultimas/2014/12/18/muere-la-actriz-italiana-virna-lisi-a-los78-anos-de-edad-3865.html.

PALAPA, Fabiola. "Falleció el poeta Gerardo Deniz", La Jornada en línea. México, 20 de diciembre de 2014, consultado el 14 de febrero de 2015, disponible en: http://www.jornada.unam.mx/ultimas/2014/12/20/fallecio-el-poeta-gerardo-deniz-8318.html.

AFP. "Muere el cantautor italiano Giuseppe Pino Mango", La Jornada en línea. México, 21 de diciembre de 2014, consultado el 14 de febrero de 2015, disponible en: http://www.jornada.unam.mx/ ultimas/2014/12/21/fallece-jane-brown-fotografa-britanica-a-los89-anos-de-edad-2091.html.

AFP y DPA. "Fallece Horacio Ferrer, el poeta del tango, en Buenos Aires”, La Jornada en línea. México 21 de diciembre de 2014, consultado el 14 de febrero de 2015, disponible en: http://www.jornada. unam.mx/ultimas/2014/12/21/fallece-horacio-ferrer-el-poeta-del-tango-en-buenos-aires-1774.html.

AFP. "Muere Joe Cocker, leyenda británica, a los 70 años de edad", $L a$ Jornada en línea. México, 22 de diciembre de 2014, consultado el 
14 de febrero de 2015, disponible en: http://www.jornada.unam. $\mathrm{mx} /$ ultimas/2014/12/22/muere-joe-cocker-leyenda-britanica-alos-70-anos-de-edad-5096.html.

AP. "Luise Rainer, ganadora de dos Óscar, muere a los 104 años”, La Jornada en línea. México, 30 de diciembre de 2014, consultado el 14 de febrero de 2015, disponible en: http://www.jornada.unam. $\mathrm{mx} /$ ultimas/2014/12/30/luis-rainer-ganadora-de-dos-oscar-muere-a-los-104-anos-2260.html.

TEJEDA, Armando G. "La gloria del Quijote sigue en pie ante el horror que nos cerca: JEP”, La Jornada. Núm. 9229, año 26, México, 24 de abril de 2010, p. 6, consultado el 14 de octubre de 2014, disponible en: http://www.jornada.unam.mx/2010/o4/24/cultura/ao4n1cul.

CORRESPONSALES. "Marchas en 25 estados para pedir justicia por Ayotzinapa”, La Jornada. Núm. 10642, año 31, México, 9 de octubre de 2014, p. 5, consultado el 28 de octubre 2014, disponible en: http://www.jornada.unam.mx/2014/10/o9/politica/o05n1pol. 